\section{Health information literacy awareness and capacity building: Present and future}

Terri Ottosen $(1)$

University of North Carolina at Chapel Hill, USA

Nandita S. Mani 1 )

University of North Carolina at Chapel Hill, USA

Megan N. Fratta

University of North Carolina at Chapel Hill, USA
International Federation of

Library Associations and Institutions

2019, Vol. 45(3) 207-215

(C) The Author(s) 2019

Article reuse guidelines:

sagepub.com/journals-permissions

DOI: |0.| | 177/03400352 | 985744 |

journals.sagepub.com/home/ifl

@SAGE

\begin{abstract}
Health literacy is increasingly important in today's complex information ecosystem, both nationally and globally. Across the world, whether people live in "information rich" or "information poor" societies, the role of our profession is a vital one. In the developed world, the ubiquitous nature of health information creates a wealth of accessible content and simultaneously has created confusion as to what information is reliable, how health information can be utilized, and whether or not information is produced in a meaningful manner. In the developing world, content may be non-existent, culturally inappropriate or inaccessible in terms of language and other barriers. In order to mitigate the health information crisis we are now facing, we need to collaborate and respond to the challenges raised by the complexity of health information. Librarians and other information professionals can and must play an important role in improving health literacy in their communities. This paper considers international efforts towards improving health in both information poor and information rich settings, including work showcased in recent years at IFLA's Health \& Biosciences Libraries Section Open Sessions at the World Library \& Information Congress (WLIC). It discusses health literacy in the US and other developed economies, and looks in detail at innovative work by the University of North Carolina at Chapel Hill (UNC)where the Health Sciences Library (HSL), a part of the University Libraries, has strengthened efforts surrounding health literacy in local communities and throughout the state. This paper provides examples of how to partner with multiple constituencies on health literacy and discusses future opportunities for growth and engagement.
\end{abstract}

\title{
Keywords
}

Community engagement, consumer health, health information, health literacy, healthy communities, population health

Submitted: 29 November 2018; Accepted: 15 March 2019.

\section{International efforts in health literacy}

Health literacy is increasingly important in today's complex information ecosystem, both nationally and globally. Across the world, whether people live in "information rich" or "information poor" societies, the role of our profession is a vital one (Feather, 2017). However, in a report from the Roundtable on Health Literacy regarding health literacy efforts around the world, Andrew Pleasant (2013) notes that
"There is not a global organization for health literacy researchers, practitioners, and policymakers. Therefore, there is no known structure through which to contact practitioners, researchers, academics, and

\section{Corresponding author:}

Nandita S. Mani, University of North Carolina at Chapel Hill, 335

S. Columbia Street, Chapel Hill, North Carolina 27599, USA.

Email: nanditam@unc.edu 
policymakers working with health literacy". Last year, at the Institute for Healthcare Advancement (IHA) Annual Health Literacy Conference in May 2018, this was addressed when a new health literacy association was formed, called the International Health Literacy Association (IHLA, 2018). At IHLA, a call for the formation of interest groups was announced, which led the Community Engagement and Health Literacy Librarian at the University of North Carolina at Chapel Hill, Health Sciences Library (HSL), to form the "Librarians Advancing Health Literacy" interest group. It is hoped that this group will serve in a networking and advisory capacity for other librarians interested in health literacy. This group could serve as a sounding board for new ideas, identification of health information resources, and sharing best practices from a global perspective that includes cultural awareness.

A variety of health literacy awareness initiatives and programs are occurring around the world. In the first European Health Literacy Survey, data were gathered in 2011 in eight countries: Austria, Bulgaria, Germany, Greece, Ireland, the Netherlands, Poland, and Spain. The survey was implemented as a population study, with 1000 randomly sampled members of the public aged 15 years and older, for each country, with a total sample population of 8000 people. The survey established four levels of health literacy: "insufficient", "problematic", "sufficient", and "excellent". Findings include that "at least 1 in $10(12 \%)$ respondents showed insufficient health literacy and almost 1 in 2 (47\%) had limited (insufficient or problematic) health literacy" although this varied by country (Sørensen et al., 2015: 1053). These findings demonstrate the internationality of the issue, as well as the challenge facing health professionals and policy makers throughout the world. In the publication Health Literacy: The Solid Facts, the World Health Organization (Kickbusch et al., 2013) highlights that most evidence, until recently, has been generated from the US. However, the European Health Literacy Survey has "generated a rich new source of high-quality data on the comprehensive health literacy of general populations that enables comparisons both within and between countries and has made major inequities visible" (Kickbusch et al., 2013: iv).

In this context, IFLA is playing a leading role. Over the last two years, it has been consulting on a new Global Vision to shape the future of our profession. Significantly, the Global Vision discussion includes among its top 10 highlights the observations that libraries are:
- deeply committed to core roles in supporting literacy, learning and reading;

- focused on our communities;

- eager to work more collaboratively and develop strong partnerships.

Apart from the book by its Chair, Professor Maria Musoke (2016), IFLA's Health \& Biosciences Libraries section has showcased work in health information literacy in the developing world including Musoke and Namugera (2014), Naidoo (2016), Namuleme et al. (2017) and Nwafor-Orizu (2018).

Interesting collaborative projects that aim to improve health literacy and enable informed medical decision-making exist. In the UK, the CILIP Health Libraries Group and Health Education England's Library and Knowledge Services began "A Million Decisions" joint campaign to ensure that the more than one million healthcare-related decisions made each day in the National Health Service are evidence based (CILIP, 2016). Another important organization to note is Healthcare Information for All (HIFA), which is a global health network of over 18,000 members from diverse fields including health workers, librarians, publishers, researchers, and policy makers who are "committed to the progressive realization of a world where every person has access to the healthcare information they need to protect their own health and the health of others" (Healthcare Information for All, n.d.). Launched by the Association for Health Information and Libraries in Africa (AHILA), Global Healthcare Information Network, and other partners, at the 10th AHILA Congress in Mombasa, Kenya in 2006, HIFA is now comprised of more than 2500 organizations across 178 countries worldwide, with one-third based in Africa, one-third in Europe, and one-third in the rest of the world. A particular initiative, the HIFA Voices Database, aims to tackle information poverty by capturing the collective knowledge of participants in the HIFA discussion forums (Pakenham-Walsh, 2014).

\section{Health literacy in the United States}

The ubiquitous nature of health information is both a benefit and burden for health consumers; freely available health information on the Internet and a wide variety of media platforms allow access to multitudes of information. However, that wealth of information can be questionable, inaccurate, and overwhelming, particularly for those with low health literacy or fluency. In their systematic review of health literacy interventions and outcomes, Berkman et al. (2011) found that low health literacy is linked to higher risk 
of death and more emergency room visits and hospitalizations. Furthermore, beyond individual impact low health literacy also significantly impacts the larger society and the healthcare system as a whole, with a cost to the US economy estimated between $\$ 106$ and \$238 billion per year (Vernon et al., 2007). Librarians can help by promoting awareness of the issue of low health literacy as well as help to increase health literacy skills by building capacity for understanding where and when to seek health information and how to effectively evaluate information found.

Libraries of all types contribute in myriad ways to the quality of life of communities. Libraries are a welcoming place, for the benefit of everyone, which makes them a natural location for people to connect and seek answers and assistance to help function in society. Public libraries provide training in the critical skills of literacy and lifelong learning and have stepped up to answer questions and provide technical assistance with navigating the health insurance marketplace, especially after the Affordable Care Act was enacted (Malachowski, 2014; Vardell, 2015). It is a natural extension of these capacities for public libraries to also support the health literacy needs of communities. Health literacy is unique in that possessing these skills can mean the difference between poor and good health (Kickbusch et al., 2013). However, only about $12 \%$ of the English-speaking adult population in the United States is considered proficient in health literacy skills (Kutner et al., 2006). Librarians have an important role to play and can assist people in locating health information, learn to critically evaluate whether information is authoritative and reliable, and to support health literacy in their communities. Given the focus on preventative medicine and increase in patient participation in shared decision making with health care providers, patients are now grappling with more complex health information needs. This paper serves as a call to information professionals and librarians working in all types of libraries throughout the world to become proactive and involved in health information literacy training in order to empower their communities.

\section{What is health literacy?}

Various definitions of health literacy exist, though a widely used definition by the US Department of Health and Human Services is "the degree to which individuals have the capacity to obtain, process, and understand basic health information needed to make appropriate health decisions" (Ratzan and Parker, 2000). In 2008 the internationally-attended Calgary Institute on Health Literacy Curricula developed a definition and rationale for the development of a health literacy curriculum. The Calgary Charter on Health Literacy defines health literacy as:

the use of a wide range of skills that improve the ability of people to act on information in order to live healthier lives. These skills include reading, writing, listening, speaking, numeracy, and critical analysis, as well as communication and interaction skills (Coleman et al., 2010: 1).

In the manual for clinicians, Health Literacy and Patient Safety: Help Patients Understand, Weiss (2007: 13) explains that "most clinicians are surprised to learn that literacy is one of the strongest predictors of health status". He reports (p.13) that "all of the studies that investigated the issue report that literacy is a stronger predictor of an individual's health status than income, employment status, education level, and racial or ethnic group". As every individual will face a health issue at some point in our lives, health literacy skills are crucial in order to make informed health decisions and to navigate and interact with the health care system. As health care gets more complex and places more demand and participation in decision making on patients and their families, health literacy skills become increasingly important, impacting the overall health status of people.

Over time, there has been growing recognition that health literacy is an interaction; a two-way communication process that requires health professionals to have an awareness of the problem of low health literacy and its impact on their patients. Writing on "The evolving concept of health literacy", Nutbeam (2008) emphasized that achieving good health literacy is not simply a matter of getting health information to those that need it; it also requires developing the confidence to act on that gained knowledge to make informed health care decisions. The idea is to use communitybased educational outreach to help the individual with their personal health decisions, but also to tackle the social determinants of health that can impact the larger population. Nutbeam argues that improving individual health and health literacy skills can have additional positive effects on communities and the social determinants of health. Through this education, librarians can help people understand the effects of low health literacy on their personal health status and empower them to use information to reduce health disparities.

\section{Roles for librarians and other information professionals}

With increased access to freely available databases and websites, today's information environment has 
shifted from one of patron dependence on libraries and librarians as gatekeepers to information and knowledge, to one of self-driven information seeking. Patients have shifted from passive recipients to active consumers of health information (McMullan, 2006). Instead of relying on librarians for mediated searches of the literature, often in books and journals behind paywalls, a great majority of people now have access to a wide range of freely available databases like PubMed/MEDLINE, consumer health sites such as MedlinePlus, and online support groups. As more information becomes freely available, this can have both positive and negative impact on information users. Increasingly, patients want to be able to read what their doctors are reading, look at new research being conducted on a health issue, or engage in a meaningful discussion with members of their health care team in order to make informed choices to improve their health status. With the abundance of information available, many people are facing information overload, which requires adapting to and processing of never-ending streams of new information. Another factor compounding the problem of health literacy is the disparity in access to technology. Limited access to technology in turn, exacerbates literacyrelated disparities, "with lower literate patients being less likely to own smartphones or to access and use the Internet, particularly for health reasons", according to Bailey et al. (2015: 3083). The authors also found that patients with adequate health literacy are more likely to access the Internet from their home and use the Internet for accessing health information and communicating with providers than patients with marginal or low literacy. Libraries help to reduce this disparity by providing access to computers and other technology as well as assistance in their use; therefore, programming on health literacy is an equally natural fit.

Libraries are a natural place for community members to get access to the wide range of information available, and to seek assistance from librarians to support lifelong learning and skill development. Long before the term "health literacy" was applied to this area, librarians actively answered consumer health questions and provided patient education (Whitney et al., 2017). Librarians know their local communities and can engage people and connect them to resources. A Digital Inclusion Survey conducted in 2014 by the Information Policy \& Action Center found that $60 \%$ of public libraries surveyed helped patrons identify health insurance resources, $58 \%$ helped patrons locate and evaluate free online health information, and $48 \%$ helped patrons understand specific health or wellness topics, while $23 \%$ of those libraries surveyed, offered fitness classes and $18 \%$ offered selected health screening services (Bertot et al., 2015). Public librarians have positive impact on individuals, which in turn may contribute to better overall health in the community's population. According to a survey conducted in 2018 on Pennsylvania public libraries, respondents indicated they frequently interacted with patrons around health and social concerns. "Public libraries are free and accessible to all and are centers of community engagement and education, making them logical choices as partners for improving population health. Library staff members routinely assist patrons with unmet health and social needs" (Whiteman et al., 2018: 1). The report also focuses on the impact libraries might have on the social determinants of health, which includes housing, employment, and education. The study investigated the frequency and methods library staff members use and are familiar with to address the social determinants of health in order to "establish the feasibility of partnering with public libraries to improve population health" (Whiteman et al., 2018: 2). The authors believe that their research can be extended nationally to inform future partnerships between public libraries and the public health sector. In the conclusion of the paper, it was found that "Although at least $40 \%$ of respondents offered some health programming at their library branch, their offerings did not meet the high level of need reflected in common patron inquiries" (Whiteman et al., 2018: 1). This indicates there is enormous potential for librarians to serve a critical need in their communities, which will continue to evolve and will require training and collaboration.

\section{Public libraries}

Public librarians can provide training on finding and evaluating reliable and authoritative health information on the Internet, as well as helping people be prepared to interact with their health care providers through asking questions and engaging in clear communication techniques with practice and role-play. One example of this is the "Engage for Health" program in Pennsylvania. This was a community health program designed to encourage people to take an active role in their health care. The program was piloted in 16 Pennsylvania public libraries and the toolkit is freely available for other libraries to use in their communities (National Network of Libraries of Medicine, 2017). In June 2013, attendees at the American Library Association were called to action by President Barack Obama to support the public's health information needs and assist with signing up for health insurance on the online marketplace created 
by the ACA (Whitney et al., 2017). Public libraries met the call with varying capacities for support, with very few (only 5\%) thinking they should not play a role in the ACA (Kohn, 2013). In 2017, during National Public Health Week, the Public Library Association (PLA) highlighted the work public libraries do in advancing the health and health literacy of Americans. PLA encouraged public libraries to post and share their health-related success stories and program examples on social media and pointed to the National Action Plan to Improve Health Literacy for more ideas and information on doing more healthrelated programming (Deutsch, 2017).The National Action Plan to Improve Health Literacy is based on two core principles: all people have the right to health information that helps them make informed decisions; and health services should be delivered in ways that are easy to understand and that improve health, longevity, and quality of life (US Department of Health and Human Services, Office of Disease Prevention and Health Promotion, 2010).

\section{Health sciences libraries}

To address patient needs around health information, health care practitioners have drawn upon the expertise of librarians in accessing, evaluating, and critically appraising scientific literature in order to make evidence-based decisions. Formalized roles for librarians in health literacy are emerging; several institutions have hired "health literacy librarians" who are responsible for outreach to consumers and health care professionals. These health literacy librarians might collaborate on a health literacy project, such as reviewing patient education discharge materials to help reduce post-surgical readmissions, or guest lecturing in credit-bearing courses on topics such as common patient signs of limited health literacy, the importance of using plain language and Teach Back, and online resources for patient education (Ottosen, 2017). Medical librarians working in academic or healthcare settings provide training, services, and resources for clinicians and health professionals to improve their ability to communicate clearly with patients (Barr-Walker, 2016). Academic health sciences librarians are also partnering with public librarians to provide health literacy training directly to members of the public and to train public librarians to build their capacity for providing health information services (Barr-Walker, 2016). For example, academic health sciences librarians provide trainthe-trainer instruction on searching consumer health websites like MedlinePlus and mental health resources (Malachowski, 2014; Radick, 2015).

\section{Building health literacy awareness and capacity at UNC}

The Health Sciences Library (HSL) at the University of North Carolina at Chapel Hill (UNC) began building its capacity for health literacy in 2017 when two new positions were created: one with responsibilities that include both community engagement and health literacy, and the other dedicated to health literacy, global health, and community outreach. At HSL, librarians have focused their health literacy efforts on both consumers and health care professionals. The consumer-focused activities include community and targeted health literacy workshops and developing online resources for health information, and translating scientific information into lay language. Services targeted to health care professionals include reviewing patient education materials and training for professionals and students on clear patient communication strategies. These activities and services help to solidify concepts and the awareness of the need for conversion of scientific or health science/medical literature into information that is understandable and potentially actionable on the patient level. These services also echo the health literacy programs that Barr-Walker (2016) identified in a literature review on health literacy and librarianship, the first literature review on this topic.

To provide health literacy training to members of the public, the HSL recognized the need to partner with groups on campus and in the community. One of the key points of contact with consumers is via a partnership with three public library systems in the surrounding counties and the School of Library and Information Science (SILS). Since 2005, SILS students have been working with HSL librarians to colead a series of computer and information literacy classes at public libraries, called the Community Workshop series (CWS) (Community Workshop Series, n.d.). The series is mostly attended by older adults, but all members of the public are welcome. HSL Librarians worked with library science students interested in health librarianship to lead classes on finding and evaluating health information. The workshops included online consumer health resources such as NLM's MedlinePlus. Xie (2012) successfully implemented a similar model of library science graduate students partnering with public libraries for health literacy instruction. The health literacy librarians also partnered with the Undergraduate Library in Fall 2018 to pilot an "Adulting 101" workshop series targeted to first-year and undergraduate students on life skills and topics they may not learn through formal coursework such as managing finances and navigating local elections. The health literacy session 
titled, "Is There a Doctor in the House? Your Prescription for Finding Quality Health Information" was attended by a mixture of undergraduate and graduate students and a second session is planned for spring 2019 focusing on mental health literacy.

Health literacy services for and collaborations with health care professionals and students focus on improving understanding between providers and their patients. By partnering with UNC's Interprofessional Education \& Practice (IPEP) office, located in the HSL, we designed a health literacy workshop which was offered and sponsored by the IPEP that included instruction on clear health communication, both using the teach-back method for verbal communication and assessing written documents, such as patient education materials. In addition, librarians review patient education materials and handouts created by providers or departments in the UNC Health Care System. Reviews focus on ascertaining reading grade level using freely available online calculators and applying the Patient Education Materials Assessment Tool (PEMAT) for suggestions on how to improve understanding through plain language and other changes to increase readability (Agency for Healthcare Research \& Quality, 2017). HSL also offers instruction for health care providers on best practices in verbal communication with patients in workshops. For example, the teach-back method ensures patients' understanding of instructions by asking, "What questions do you have?" or "Tell me how you're going to take your medicine when you get home," rather than, "Do you have any questions?" which may lead to nodding or a yes if patients are ashamed to admit they do not understand (Brega et al., 2015). Further examples of successful collaboration have included reviewing and providing suggestions and considerations for patient brochures and websites and helping a group of researchers write a plain language summary of their research for their article submission to a scholarly journal.

The UNC HSL also manages two websites in support of health literacy throughout the state. NC Health Info (Health Sciences Library at UNC-Chapel Hill, 2018a) which was launched in 2003, is HSL's consumer health website, which helps people find reliable and easy-to-understand health and medical information and services that are pertinent to North Carolinians. It links to many reputable health information sites like MedlinePlus and includes sections on managing your healthcare, providers, and services, staying healthy and safe, and medications and therapies. The other site we have been asked to lead, is specifically on health literacy for health professionals, NCHealthLiteracy.org, which was recently transferred to the
HSL by a health literacy physician expert on campus. This has afforded the library an opportunity to provide much needed health literacy tools, information, and techniques in an online environment that will be easily accessible and utilized.

\section{Future opportunities and health literacy engagement}

There are numerous ways to engage in health literacy efforts moving forward. For HSL, we plan on furthering our health literacy initiative by engaging on our campus and in our community in a variety of ways. For example, we plan to design a workshop and develop interactive online modules for teaching best practices in writing plain language or lay summaries of health or scientific information for the public or for those in health or scientific fields other than their own. Beginning in the summer of 2019, the European Union will begin requiring plain language summaries of all clinical trials. Some European journals already require these for journal article submissions. There is growing demand for access to and understanding of medical research for medical decision making and knowledge synthesis and it is anticipated that this demand will continue to grow. The US Food and Drug Administration drafted a document on guidance on the provision of plain language summaries, which is intended to "facilitate the voluntary provision of plain language summaries" for research subjects and the general public (MRCT Center, 2017).

The HSL also plans to develop interactive modules and/or videos on the teach-back method and health literacy for the health care professional. Use of the teach-back method allows healthcare providers to assess patient understanding and helps to cement the information given in patients' minds. In addition, continual work and improvements will continue for the NCHealthLiteracy.org website (Health Sciences Library at UNC-Chapel Hill, 2018b), which is targeted to healthcare professionals and students in the health sciences. This website was previously maintained by the Sheps Center for Health Services Research at UNC Chapel Hill and served as the home to the NC Program on Health Literacy. Responsibility for its maintenance and re-envisioning was transferred to HSL where a team of librarians will be updating the site with the intent of providing a central online location for health literacy efforts and outreach to the University and statewide. Information on the site will include stories from around the state of how health literacy is applied, testimonials and tutorials, specific projects and partnerships, and professional resources at the HSL and beyond, to help healthcare 
practitioners incorporate health literacy best practices in their everyday work with patients and their families. Another segment of the population we plan on engaging is in the K-12 arena. In an effort to help build health literacy skills and capacities of the K-12 and teen population, a health curriculum for underserved populations in North Carolina will be implemented. It will utilize and modify existing curricula developed in other successful projects such as Project SHARE at the University of Maryland (University of Maryland Health Sciences \& Human Services Library, 2018) or Nemour's Children's Hospital in Florida (Wilson, 2018). This curriculum will encompass various aspects of navigating the healthcare system, building health literacy skills and the capacity to evaluate online health information and to be active participants in their own health and wellness journeys. Our hope is that if we can start building strong health literacy skills in our students, they will build lifelong habits around information inquiry, utilization, and evaluation.

Whether you are serving members of the public, students, or health professionals, it is important for librarians to offer instruction in the search and utilization of reliable and trustworthy information. Developing critical thinking and evaluation skills in the digital environment is increasingly important in this age of information abundance and potentially biased resources. Even with limited ability to add personnel, current staff can be encouraged to participate in continuing education or other courses that will enable a base level of engagement around patient education, health literacy, and clear health communication. The Medical Library Association (MLA) has a Consumer Health Information Specialization (CHIS), which along with MLA membership is available to information professionals throughout the world (Medical Library Association, 2018). This specialization, which can be earned through taking classes approved for the CHIS, serves as an overall guide on providing consumer health information services at a library, and helps public librarians feel more comfortable with serving the general public in terms of their health information needs. Additionally, through the National Network of Libraries of Medicine (NNLM), select classes are available for free, and in some instances, regions within the NNLM offer to pay a participant's CHIS fee to MLA. NNLM also provides funding awards to libraries or community organizations to offer health information services and/or programming to increase access to and use of reliable, authoritative health information (National Network of Libraries of Medicine, n.d.).
Health information is flourishing in the online environment and information professionals are critical partners in helping to identify optimal ways of communicating complex scientific information at a level which patients and consumers will be able to understand. To be able to participate in one's own health care, patients need to know what questions to ask and how to interpret information regarding conditions and diagnoses that are pertinent to health care decision making. Librarians and information professionals can partner with health care teams to help formulate better approaches to converting complex scientific information to lay language, can help redesign patient-centered pamphlets or informational videos, design instructional approaches, provide better communication protocols for clinicians, and can partner with other institutions and organizations to help improve overall health status and reduce health disparities.

Librarians, along with community partners (e.g. school nurses, community pharmacists, utilizing dramatic arts), can have a significant impact on the promotion of health and health information fluency (Mani, 2004). Just as learning is a continual process; the same holds true with health information fluency. We need to build habits of inquiry and learning if we hope to mitigate the health literacy crisis we are now facing. Many librarians are already providing services and assistance, however, there is an overwhelming untapped opportunity for greater involvement. Libraries have always been very responsive to the needs of members of their communities and are needed now more than ever to enhance and improve the quality of life for the community they serve. All librarians and information professionals can play an important role in helping to educate and empower their communities through health literacy training and programming. The question remaining is: wherever you are, are you ready to answer the call?

\section{Declaration of Conflicting Interests}

The author(s) declared no potential conflicts of interest with respect to the research, authorship, and/or publication of this article.

\section{Funding}

The author(s) received no financial support for the research, authorship, and/or publication of this article.

\section{ORCID iD}

Terri Ottosen (1) https://orcid.org/0000-0002-1749-927X

Nandita S. Mani (1) https://orcid.org/0000-0002-0955-1066 


\section{References}

Agency for Healthcare Research \& Quality (2017) The Patient Education Materials Assessment Tool (PEMAT) and User's Guide. Rockville, MD: Agency for Healthcare Research \& Quality. Available at: https://www. ahrq.gov/professionals/prevention-chronic-care/ improve/self-mgmt/pemat/index.html (accessed 27 November 2018).

Bailey SC, O’Conor R, Bojarski EA, et al. (2015) Literacy disparities in patient access and health-related use of Internet and mobile technologies. Health Expectations 18(6): 3079-3087.

Barr-Walker J (2016) Health literacy and libraries: A literature review. Reference Services Review 44(2): 191-205.

Berkman ND, Sheridan SL, Donahue KE, et al. (2011) Health literacy interventions and outcomes: An updated systematic review. Evidence Report/Technology Assessment (199): 1-941.

Bertot JC, Real B, Lee J, et al. (2015) 2014 Digital Inclusion Survey: Survey Findings and Results. College Park, MD: University of Maryland, Information Policy \& Access Center.

Brega AG, Bernard J, Mabachi NM, et al. (2015) Health Literacy Universal Precautions Toolkit. 2nd edn. Agency for Healthcare Research \& Quality. Available at: https://www.ahrq.gov/professionals/quality-patientsafety/quality-resources/tools/literacy-toolkit/healthlit toolkit2.html (accessed 27 November 2018).

CILIP (2016) A million decisions. London: CILIP. Available at: https://www.cilip.org.uk/page/amilliondecisions (accessed 9 February 2019).

Coleman C, Kurtz-Rossi S, McKinney J, et al. (2010) The Calgary Charter on Health Literacy: Rationale and Core Principles for the Development of Health Literacy Curricula. Montreal: The Centre for Literacy.

Community Workshop Series (n.d.) Available at: http:// cws.web.unc.edu/ (accessed 28 November 2018).

Deutsch L (2017) Public libraries play vital role in advancing health literacy. American Library Association. Available at: http:/www.ala.org/news/member-news/ 2017/04/public-libraries-play-vital-role-advancinghealth-literacy (accessed 27 November 2018).

Feather J (2017) The Information Society: A Study of Continuity and Change. 6th edn. London: Facet.

Health Sciences Library at UNC-Chapel Hill (2018a) NC Health Info. Available at: http://www.nchealthinfo.org/ (accessed 28 November 2018).

Health Sciences Library at UNC-Chapel Hill (2018b) NC Health Literacy. Available at: http://nchealthliteracy.org (accessed 27 November 2018).

Healthcare Information for All (n.d.) Overview. Healthcare Information for All. Available at: http://www.hifa.org/ about-hifa/overview (accessed 10 February 2019).

International Health Literacy Association (IHLA) (2018) International Health Literacy Association. Available at: http://www.i-hla.org/ (accessed 28 November 2018).
Kickbusch I, Pelikan JM, Apfel F, et al. (eds) (2013) Health Literacy: The Solid Facts. Geneva: World Health Organization.

Kohn K (2013) Taking our pulse: Reactions to ACA from Illinois Libraries. ILA Reporter 31(6): 8-11.

Kutner M, Greenberg E, Jin Y, et al. (2006) The Health Literacy of America's Adults: Results from the 2003 National Assessment of Adult Literacy. Washington, DC: US Department of Education, National Center for Education Statistics.

McMullan M (2006) Patients using the Internet to obtain health information: How this affects the patient-health professional relationship. Patient Education and Counseling 63(1/2): 24-28.

Malachowski M (2014) Obamacare and the proper role of public libraries in health literacy. Computers in Libraries 34(1): 4-9.

Mani NS (2004) From information literacy to information fluency. American Libraries 35(2): 30.

Medical Library Association (2018) Consumer Health Information Specialization. Available at: https://www. mlanet.org/page/chis (accessed 28 November 2018).

MRCT Center (2017) Draft FDA Guidance on Provision of Plain Language Summaries. MRCT Center of Brigham and Women's Hospital and Harvard. Available at: https://mrctcenter.org/wp-content/uploads/2017/06/ 2017-06-13-MRCT-Draft-FDA-Guidance-Return-ofAggregate-Results.pdf (accessed 28 November 2018).

Musoke MGN (2016) Informed and Healthy. Amsterdam: Academic Press.

Musoke MGN and Namugera L (2014) Librarians' contribution to social change through information provision: The experience of Makerere University Library. In: IFLA WLIC 2014, Lyon, France, 16-22 August 2014. Available at: http://library.ifla.org/1054/ (accessed 26 February 2019).

Naidoo P (2016) Connecting communities: From the librarian to the dietician to the patient. In: IFLA WLIC 2016, Columbus, OH, USA, 13-19 August 2016. Available at: http://library.ifla.org/id/eprint/1352 (accessed 28 February 2019).

Namuleme RK, Tarpley MJ, Umutesi A, et al. (2017) Increasing access to HIV/AIDS information in Rwanda and Uganda through social media: A call to action for health librarians. In: IFLA WLIC 2017, Wrocław, Poland, 19-25 August 2017. Available at: http:// library.ifla.org/id/eprint/1630 (accessed 28 February 2019).

National Network of Libraries of Medicine (n.d.) Funding Opportunities. National Network of Libraries of Medicine. Available at: https://nnlm.gov/funding (accessed 27 November 2018).

National Network of Libraries of Medicine (2017) About Engage for Health. NNLM.gov. Available at: https:// nnlm.gov/mar/guides/programming-class/engagefor health (accessed 10 April 2019).

Nutbeam D (2008) The evolving concept of health literacy. Social Science \& Medicine 67(12): 2072-2078. 
Nwafor-Orizu EO (2018) Controlling non communicable diseases in Nigeria through health library outreach projects. In: IFLA WLIC 2018, Kuala Lumpur, Malaysia, 24-30 August 2018. Available at: http://library.ifla. org/id/eprint/2185 (accessed 28 February 2019).

Ottosen T (2017) Health Literacy. UNC University Libraries. Available at: https://guides.lib.unc.edu/health literacy (accessed 25 November 2018).

Pakenham-Walsh N (2014) HIFA Voices tackles information poverty to improve global health. Available at: https://www.elsevier.com/connect/hifa-voices-tacklesinformation-poverty-to-improve-global-health (accessed 10 February 2019).

Pleasant A (2013) Health Literacy Around the World: Part 1 Health Literacy Efforts Outside of the United States. Washington, DC: National Academies Press. Available at: https:/www.ncbi.nlm.nih.gov/books/NBK202445/ (accessed 10 June 2019).

Radick L (2015) Improving health literacy, one public library at a time. American Libraries. Available at: https://americanlibrariesmagazine.org/2015/10/30/ improving-health-literacy-public-library/ (accessed 10 June 2019).

Ratzan SC and Parker RM (2000) Introduction. In: Selden CR, Zorn M, Ratzan SC, et al. (eds) National Library of Medicine Current Bibliographies in Medicine: Health Literacy (no.2000 -1). Bethesda, MD: National Institutes of Health.

Sørensen K, Pelikan JM, Röthlin F, et al. (2015) Health literacy in Europe: Comparative results of the European health literacy survey (HLS-EU). European Journal of Public Health 25(6): 1053-1058.

University of Maryland Health Sciences \& Human Services Library (2018) Project SHARE Curriculum. Available at: http://guides.hshsl.umaryland.edu/project share/ (accessed 28 November 2018).

US Department of Health and Human Services, Office of Disease Prevention and Health Promotion (2010) National Action Plan to Improve Health Literacy. Washington, DC: Department of Health and Human Services.

Vardell E (ed.) (2015) The Medical Library Association Guide to Answering Questions about the Affordable Care Act. Lanham, MD: Rowman \& Littlefield.

Vernon J, Trujillo A, Rosenbaum S, et al. (2007) Low Health Literacy: Implications for National Health Policy. Storrs, CT: University of Connecticut, National Bureau of Economic Research.

Weiss BD (2007) Health Literacy and Patient Safety: Help Patients Understand. Manual for Clinicians. 2nd edn. Chicago, IL: American Medical Association.

Whiteman ED, Dupuis R, Morgan AU, et al. (2018) Public libraries as partners for health. Preventing Chronic Disease 15.

Whitney W, Keselman A and Humphreys B (2017) Libraries and librarians: Key partners for progress in health literacy research and practice. Information Services \& Use 37(1): 85-100.
Wilson J (2018) Nemours launches new national health literacy curriculum for high schools. Nemours Children's Health System. Available at: https://www. nemours.org/about/mediaroom/press/dv/nemourslaunches-new-national-health-literacy-curriculum.html (accessed 26 November 2018).

Xie B (2012) Improving older adults' e-health literacy through computer training using NIH online resources. Library \& Information Science Research 34(1): 63-71.

\section{Author biographies}

Terri Ottosen, MLIS, AHIP is the Community Engagement and Health Literacy Librarian at the Health Sciences Library at the University of North Carolina, Chapel Hill. She has over 20 years of experience as a health sciences librarian, specializing in consumer health and health literacy for more than half her career. She has extensive experience providing training to public librarians and library staff in providing consumer health information services to the general public, through her previous role as Consumer Health Coordinator at the National Network of Libraries of Medicine, Southeastern Atlantic Region. She promotes clear health communication and health literacy awareness to faculty, staff and students at UNC and is focused on finding ways to promote health literacy and patient involvement into interprofessional (IPE) efforts.

Nandita S. Mani, PhD, MLIS is the Associate University Librarian for Health Sciences and Director of the Health Sciences Library. Mani oversees the UNC Health Sciences Library (HSL) which is the primary library for the University's schools of dentistry, medicine, nursing, pharmacy, and public health. It also serves the UNC Medical Center and the North Carolina Area Health Education Centers (NC AHEC), a statewide program for clinical education and health services. Mani has provided consumer health information outreach to consumers, support groups, and students, has editorial responsibilities including as Managing Editor for Advances in Chronic Kidney Disease, as an Assistant Editor for Consumer Health on the Internet, and has published in the areas of information science, health literacy, and instructional design and technology.

Megan Fratta, MLS is the Community Outreach and Global Health Librarian and provides health literacy training to students and faculty and leads workshops for the public on how to find and evaluate health information. She also works with interdisciplinary global health teams to provide health information access at UNC's global research and practice sites. Megan was an Associate Fellow at the National Library of Medicine from 2016-2017 where she trained on NLM's consumer health information resources. 